\title{
İçsel Pazarlama Uygulamalarının Örgütsel Vatandaşlık Davranışına Etkisi: Kamu Kurumunda Bir Uygulama
}

\author{
The Effect of Internal Marketing Practices on Organizational Citizenship \\ Behaviour: An Application in a Public Institution
}

\section{Öz}

Kurumlar, çalışanlarının gelişiminde ve kurum içi iş süreçlerinin daha etkin ve verimli bir şekilde yürütülmesinde çeşitli içsel pazarlama faaliyetleri organize etmektedirler. Yürütülen bu faaliyetlerle çalışanların kuruma bağhlıklarını arttırmayı ve daha başarılı bir iş süreci yürütmelerini sağlamayı hedeflemektedirler. Bu çalışmanın amacı yürütülen içsel pazarlama faaliyetlerinin çalışanların örgütsel vatandaşlık (diğergamlık) davranışı gösterme eğilimleri üzerindeki olası etkisini araştırmaktır. Çalışmanın evrenini Trabzon ilinde bulunan bir kamu kurumunun çalışanları oluşturmaktadır. Araştırma modelini test etmede gereken veriler kolayda örneklem yöntemi kullanılarak anket tekniği ile toplanmış olup, 210 adet katılımcıya ulaşılmıştır.

Verilerin analiziyle elde edilen bulgular neticesinde içsel pazarlama faaliyetlerinin alt boyutların oluşturan eğitim ve gelişim boyutu ile iç iletişim alt boyutlarının örgütsel vatandaşlık davranışı değişkenini oluşturan bireysel vatandaşlık davranışı ve örgütsel vatandaşlık davranışı alt boyutlarnın her ikisi üzerinde pozitif ve anlaml etkilerinin olduğu gözlemlenirken, diğer alt boyutlardan ücret ve ödüllendirme boyutu ile personel güçlendirme boyutunun anlamlı etkiye sahip olmadıkları tespit edilmiştir.

\footnotetext{
Abstract

Institutions organize various internal marketing activities both in the execution of internal business processes more effectively and efficiently and in the development of their employees. With these activities, they aim to increase the loyalty of the employees to the institution and to enable them to carry out a more successful business process. The study aims to investigate the possible effects of internal marketing activities on the tendency of employees to display organizational citizenship (altruism) behaviour. The universe of the study consists of the employees of a public institution in

\section{Keywords \\ Internal Marketing, Marketing, Organizational Citizenship Behaviour}

JEL Codes: M31, M12

Submitted: $23 / 11 / 2021$

Accepted: $18 / 01 / 2022$ Trabzon. The data required to test the research model were collected by survey using convenience sampling method, and 210 participants were reached.

As a result of the findings obtained by the analysis of the data; It has been observed that the sub-dimensions of internal marketing activities: training and development and internal communication sub-dimensions have positive and significant effects on both the individual citizenship behaviour and organizational citizenship behaviour sub-dimensions, which constitute the organizational citizenship behaviour variable. It has been determined that the wage and reward dimension and the personnel empowerment dimension, which are among the other sub-dimensions, do not have a significant effect.
}

\author{
Ahmet Mutlu Akyüz \\ Doç. Dr., İ̈BF İnsan Kaynakları \\ Yönetimi Bölümü Öğretim Üyesi, \\ ahmetmutluakyuz@gmail.com \\ Orcid No: https://orcid.org/0000-0002- \\ 6406-3284
}

\begin{abstract}
Yusuf Yazıcı
Doktora Öğrencisi, Gümüşhane Üniversitesi Lisansüstü Ĕ̆itim Enstitüsü İsletme ABD yusuf.yazici@turktelekom.com.tr Orcid No: https://orcid.org/0000-0002-63553388
\end{abstract}

Article Type / Makale Türü Research Article / Araştırma Makalesi

Anahtar Kelimeler

İçsel Pazarlama, Pazarlama, Örgütsel Vatandaşlık Davranışı.

\section{Giriş}

Çalışanların örgüte yönelik olumlu duygular beslemesi işletmelerde uzun dönemli örgütsel başarıya katkı sağlamaktadır. Araştırmacıların dikkatini çeken bu durum özellikle 1980'lerden itibaren birçok araştırmaya konu olmuştur (Basım ve Şeşen, 2006: 84). Örgüte yönelik olumlu duygu göstergelerinden biri olan örgütsel vatandaşlık davranışı (ÖVD) çalışanların içinde bulundukları organizasyonun çıkarlarına yönelik destekleyici tutumlarını ifade eder (Moorman ve Blakely, 1995: 127). Bu tutumlar, çalışanlarda gönüllülük, ekstra iş, başkalarına yardım, iş yeri kurallarına uyum 
olarak ortaya çıkarak çalışanların örgüt verimliliğine olan bireysel katkılarıdır (Organ ve Ryan, 1995: 776). ÖVD ayrıca çalışanların itaat, sadakat, temsil etme ve katılım davranışları olarak da ortaya çıkabilir. Çalışanın itaat davranışı, çalışanın örgütsel yapıya, iş tanımlarına ve politikalarını düzenleyen kurallara olan saygısıdır. Sadakat davranışı, çalışanın örgütün liderleri ve örgüt yapısı ile bir bütün olarak özdeşleşmesini ve bağlılığını gösterir. Temsil etme davranışı, çalışanın içinde yer aldığı örgütü tehditlere karşı savunmasını ve örgütün itibarına katkı sağlamasını ifade eder. Örgüte katılım ise, başkaları ile yardımlaşma, bilgi paylaşımı ve süreçleri benimseyerek fikir üretmek anlamina gelir (Van Dyne vd., 1994: 767). Örgütsel vatandaşlık, genellikle üst yönetimin katı talimatlarına bağlanmadan örgüt içi değer yaratan, örgüt hedeflerini destekleyen, çalışanlar arası işbirliği sağlayan, bireysel çıkarlardan çok örgüt çıkarlarını gözeten bir kavramsal anlayıştır (Çavuş ve Biçer, 2021: 388). ÖVD çalışanların sosyal ve psikolojik durumlarının sürdürülmesine imkân sağlayarak onların görev performanslarını artırır (Chan ve Kuok, 2020:116). Bütün bu özellikler, örgüt içi üretkenliği artırarak diş müşteri memnuniyetinin oluşmasını sağlar. Mevcut müşterilerin elde tutulmalarına katkı sağlayarak kurumun finansal performansını artırır. Eksikliği durumunda ise işten ayrılmalara sebep olabilmekte ve kurum içi personel devir hızına olumsuz etkisi olabilmektedir (Amin vd., 2020:110).

Literatürdeki çalışmalarda, ÖVD kavramının boyutları konusunda bir fikir birliği olmayıp, yaklaşık otuza yakın farklı boyutta incelendiği gözlemlenmektedir (Podsakoff vd., 2000: 516). Bazı araştırmalar (Amah, 2020, Demirel ve Güner, 2015, İplik vd., 2014, Lee ve Allen, 2002, Williams ve Anderson, 1991) ÖVD'nin bireysel ve örgütsel yönüne ağırlık vermiştir. Williams ve Anderson (1991) çalışmalarında ÖVD'yi iki boyutlu bir yapıda değerlendirmiştir. ÖVD'nin örgütsel boyutu çalışanların genel olarak örgütün formal kurallarına olan faydalı katkılarını ifade etmektedir. ÖVD'nin bireysel boyutu ise çalışanların örgütün faydasına olan kişisel katkılarını gösterir. ÖVD, çalışanlar ile örgüt arasındaki etkileşimde bir denge unsuru olarak ortaya çıkar. Bu dengenin oluşumunda örgütsel boyut, çalışanların örgütün iş özellikleri ve iş karakteristikleri hakkındaki düşüncelerinin bir fonksiyonunu ifade ederken, bireysel boyut ise çalışanların bireysel yardımlaşmasına yöneliktir. Çalışan, resmi iş tanımının dışına çıkarak kendi isteğine bağlı olarak gönüllü davranışlar sergileyebilmekte ve örgüt etkinliğine dolaylı etkisi bulunabilmektedir (Lee ve Allen, 2002: 132). Örgütün sosyal imkânları çerçevesinde çalışanlar, işbirliği içinde yardımlaşarak birbirlerini gözetebilirler. Örgütsel boyutta çalışanlar, örgütü olası tehditlere karşı gözetirler. Örgütün gelişimi için çalışanlar iş süreçlerine aktif katılım sağlayabilirler (İplik vd., 2014: 112).

ÖVD anlayışına sahip çalışanlar kurumu kendi şahsi işyerleri gibi gördüklerinden kurum başarısında resmi ve belirlenmiş görevlerin ötesinde bir çaba göstermeleri gerektiğinde bundan çekinmezler (Ghalavi ve Nastiezaie, 2020: 244). Sosyal yaşamda iş ortamları sürekli aynı düzeyde olamamakta, zaman zaman kırılganlıklar gösterebilmektedir. ÖVD, iş arkadaşlığını güçlendirerek organizasyonel etkileşimi geliştirir. Çalışanlar ile örgüt arasındaki uyum becerisini artıran bir özelliğe sahiptir (Amah, 2020: 359). Bu sebepledir ki, kurum yöneticileri çalışanların vatandaşlık davranışı algılarını geliştirmek amaçlı kurum içi faaliyetler planlayabilir. Kurumların çalışanlarına yönelik bir dizi içsel süreç uyguladığı fark edildiği için bu anlamda birçok araştırma bu yöne odaklanmış vaziyettedir (Zhao vd., 2019: 371).

Günümüz rekabet ortamında işletmelerin uzun dönemli varlıklarını sürdürebilmeleri insan kaynağına verdikleri önem ile mümkün olabilir. Uzun dönemli kar ise daha çok müşterilerin organizasyona sadakatleri ile mümkündür. Örgütün müşteri portföyünün artırılmasının ancak örgüt çalışanlarının kaliteli hizmet sunumları ile mümkün olabileceğinin fark edilmesi ile örgütlerde iç müşteri kavramı gelişmiştir (Caruana ve Calleya, 1995: 108). Ürünlerini uzun dönemde satın alan tatmin edilmiş müşteriler oluşturabilmenin yolu yine tatmin olmuş çalışanlardan geçmektedir. Özellikle hizmet işletmelerinde müşteri tatmini sağlanması çalışanların yetenek ve kabiliyetlerinin geliştirilmesi ile mümkün olabilmektedir. Bunun bilincinde olan işletme yöneticileri çalışanların müşteri yönlü davranışlar geliştirmelerine yardımcı olmak amacıyla çeşitli uygulamaları daha bilinçli ve programlı bir şekilde uygulamaya koymaktadırlar. Müşteri yönlü davranışlar geliştirmeleri amacıyla çalışanların motive edilmesi, farklı bölümlerle olan koordinasyonlarının sağlanması, şirket içi bir bütünlük sağlanması, değişime olan direncin ortadan kaldırılarak şirket 
stratejilerinin daha etkin bir şekilde yürütülmesi amacıyla yürütülen faaliyetler alan yazınında bir bütün olarak içsel pazarlama şeklinde tanımlanmaktadır (Ay ve Kartal, 2003: 16). Hizmet kalitesinin iyileştirilmesini amaçlayan içsel pazarlama, bir kuruluşun müşterilerine sunduğu hizmetin kalitesini artırmak için çalışanlarına verdiği eğitim, gelişim ve motive edici eylemler olarak tarif edilebilir (Ahmad ve Al-Borie, 2012: 87). Burada temel fikir etkili hizmet için motive olmuş ve müşteri memnuniyetinin önemi bilincine sahip çalışanlar oluşturmaktır (Ahmed ve Rafiq, 1995: 33). Organizasyonun hizmet sunduğu müşterilerini etkilemek için çalışanları üzerindeki çabalarının bir bütünüdür, denebilir (Gounaris, 2006: 432). Çalışanların becerileri geliştirilerek işe yönelik tutumlarının örgüt vizyonu ve kültürüne uygun hale getirilmesi gerekmektedir (Arnett vd., 2002: 87). Bunun sağlanması için organizasyonun insan kaynakları yönetimi politikalarının pazarlama perspektifinden ele alınması gerekmektedir (George, 1990: 64). İçsel pazarlamanın, gerek pazarlama gerekse de insan kaynakları yönetiminin bir alt başlığı olduğu söylenebilir (Cioclov vd., 2016: 68). Bu bağlamda, literatür incelendiğinde içsel pazarlama ile ilgili çalışmalarda her bir çalışmanın içsel pazarlama konusunu farklı bir perspektiften ele aldığı görülebilir. Geniş çerçevede değerlendirildiğinde içsel pazarlamanın; ücret, çalışan desteği, yönetici, çalışma koşulları, iş güvenliği, çalışma ortamı, çalışan seçimi, çalışan eğitimi ve gelişimi, iş tasarımı, iş tanımı, çalışanı ödüllendirme, açıklık, geri bildirim, hizmet kalitesi, örgüt vizyonu, stratejik ödüllendirme, iç iletişim, liderlik anlayışı, vb. gibi çeşitli kavramlarla ele alındığı görülmektedir (Ahmad ve Al-Borie, 2012: 84). Bu unsurların her biri çalışanların iş tatminini, performansını ve hizmet kalitesini artırarak çalışanlar ile örgüt arasında daha iyi bir bağ kurmayı hedeflemektedir.

Bu çalışmada içsel pazarlama uygulamaları olarak eğitim ve gelişim, ücret ve ödüllendirme, personel güçlendirme ve iç iletişim boyutları belirlenmiş olup bu değişkenlerin örgütsel vatandaşlık davranışının bireysel ve örgütsel boyutları üzerine etkisi araştırılmıştır. Bu doğrultuda konu ile ilgili literatüre yer verilerek araştırmanın modeli çerçevesinde hipotezleri test edilmiştir.

\section{Literatür Taraması}

Hizmet sektöründe çalışanların rolünün önemi bilinmektedir. Çalışanların örgüt değerlerine yönelik bilgi ve becerilerinin geliştirilmesi, ayrıca çalışanların kurumsal çevreye adapte edilmeleri içsel pazarlamanın başlıca amaçları arasındadır (Liu vd., 2020: 292). Bu sayede çalışanların örgüte yönelik bağlılıkları daha da geliştirilebilir.

Örgüte yönelik bağlılık veya vatandaşlık davranışı, kurumun içsel iletişiminde önemli bir kavramdır. Çalışanların gönüllü davranışları memnuniyetlerinin göstergesidir. Birey belirli olaylarla özdeşleşir ve bunun sonucunda evrimleşir (Mac ve Shirley, 2015: 5). Duyarlı çalışanların içsel motivasyonları güçlü olup kurum çıkarları doğrultusunda kendiliğinden harekete geçerler. Bu durum çalışanın örgüte yönelik bağlılığının bir sonucu olarak gerçekleşir (Zhao vd., 2019: 372). Daha profesyonel çalışanlar kurumlarına önemli katkılar sağlamaktadırlar (Patrick ve Paille, 2019: 2705). $\mathrm{Bu}$ sebeple çalışanların daha da uzmanlaşarak kuruma katacakları değer ve bunun belirlenmesi araştırmacılar tarafından önemli bir araştırma alanı olarak görülmektedir. Çalışanların bilgi ve becerilerinin artırılması, müşteri memnuniyetinin bilincinde olarak müşteri yönlü davranışlar geliştirmeleri, kurum vizyonunu kavrayarak ortak hedefler doğrultusunda hareket etmeleri işletmeler için arzulanandır. Çalışanların bu doğrultuda gelişimini sağlamak ancak işletmelerin içsel pazarlamaya gereken önemi vermeleri ile mümkün olabilmektedir. Planlı ve doğru bir içsel pazarlama politikası ile işlerinde uzman çalışanlar kurumun hedefleri doğrultusunda kendiliğinden ekstra emek harcamaya razı olacak ve kurumlarına yönelik bağlılıkları gelişecektir. Bu bağlılık çalışanların örgüt vatandaşı olmaları ile sonuçlanacaktır.

Konuyla ilgili literatür incelendiğinde, Zhao vd. (2019) sosyal sorumlu insan kaynakları uygulamalarının çalışanların çevreye yönelik örgütsel vatandaşlık davranışına etkisini kişi örgüt uyumu çerçevesinde araştırmış olup, insan kaynakları uygulamalarının çalışanların ÖVD üzerinde pozitif ve anlamlı bir etkisi olduğunu tespit etmişlerdir.

Liu vd. (2020) yeşil kavramı çerçevesinde uygulanılan insan kaynakları yönetiminin yeşil örgütsel kimlik ve çevreye yönelik ÖVD değişkenleri arasındaki ilişkiyi araştırmış olup, yeşil insan 
kaynakları yönetiminin çevreye yönelik örgütsel vatandaşlık davranışı üzerine anlamlı ve pozitif bir etkisi olduğunu, ayrıca yeşil örgütsel kimliğin bu etkide aracı rol üstlendiğini tespit etmişlerdir.

Patrick ve Paille (2019) insan kaynakları uygulamalarının örgütsel vatandaşlık davranışına etkisinde algılanan örgüt desteği, iş memnuniyeti ve örgütsel bağlılı̆̆ın aracı rolünü inceledikleri araştırmalarında, adalet ve ödüllendirme, yetenek gelişimi, tanıtma şeklindeki insan kaynakları uygulamalarının ÖVD üzerinde anlamlı bir etkisi olduğunu tespit etmişlerdir.

Akın (2019) insan kaynakları uygulamalarının çalışmaların iş tatmini ve örgütsel vatandaşlık davranışları üzerindeki etkisini incelediği çalışmada insan kaynakları uygulamaları olarak belirlenen seçim, teşvik, eğitim ve geliştirme uygulamalarının çalışanların ÖVD üzerinde pozitif ve anlamlı bir etkisi olduğunu ortaya koymuştur.

Pham vd. (2019) yeşil insan kaynakları uygulamalarının çalışanların çevreye yönelik örgütsel vatandaşlık davranışlarına etkisini araştırdıkları çalışmalarında eğitim, performans yönetimi, çalışan katılımı alt boyutlarının çevreye yönelik ÖVD üzerinde pozitif ve anlamlı etkileri olduğunu ortaya çıkarmışlardır.

Huang (2018) çalışmasında içsel pazarlama yönetimi, örgütsel bağlllık ve ÖVD değişkenleri arasındaki olası ilişkileri incelemiş olup, içsel pazarlama yönetiminin ve örgütsel bağl1lığın ÖVD üzerinde pozitif ve anlamlı bir etkiye sahip olduğunu bulmuştur.

Newman vd. (2016) sosyal sorumlu insan kaynakları uygulamalarının çalışanların örgütsel vatandaşlık davranışları üzerindeki etkisini ve örgütsel kimliğin bu ilişkideki olası aracı rolünü incelemişlerdir. Çalışma sonucunda çalışan odaklı İK ve genel anlamda kurumsal sosyal sorumluluk uygulamalarının çalışanların örgütsel vatandaşlık davranışları üzerinde pozitif ve anlamlı etkileri olduğu tespit edilmiştir.

Pratiwi ve Salsabiela (2015) çalışmalarında stratejik insan kaynakları yönetimi uygulamalarının çevreye yönelik örgütsel vatandaşlık davranışına anlamlı katkıları olduğunu tespit etmişlerdir.

Demirel ve Güner (2015) yapmış oldukları araştırmada işletmelerde iç müşteri ilişkileri olarak belirlenen liderlik, işbirliği ve iletişim, teknolojik yeterlilik, iç müşteri odaklılık ve çalışan tatmini boyutlarının çalışanların bireysel ve örgüte yönelik örgütsel vatandaşlık davranışlarına anlamlı etkileri olduğunu ortaya koymuşlardır.

Akgemci ve Koçyiğit (2013) çalışmalarında eğitim ve geliştirme faaliyetlerinin ÖVD üzerindeki etkileri araştırılmış olup, eğitim ve geliştirme faaliyetlerinin alt boyutlarından algılanan eğitim olanakları, eğitim programlarındaki öğrenme motivasyonu ve eğitimden beklenen bireysel kazançlar boyutlarının örgütsel vatandaşlık davranışını pozitif yönlü etkilediği tespit edilmiştir. Öte yandan, eğitim için algılanan amir desteği, çalışma arkadaşlarının desteği ve eğitim ile ilgili kariyer beklentileri boyutlarının ÖVD üzerinde anlamlı bir etkiye sahip olmadığı tespit edilmiştir.

Wei vd. (2010) çalışmalarında yüksek performanslı insan kaynakları uygulamaları olarak belirlenen iç kariyer fırsatları, eğitim, çalışan güvenliği, katılım ve iletişim, hassas seçim, teşvik bedeli alt boyutlarının çalışanların örgütsel vatandaşlık davranışları üzerinde anlamlı bir etkisi olmadığı tespit edilmiştir.

\section{Metodoloji}

\section{1. Araştırmanın Modeli ve Hipotezleri}

İşlerinde daha verimli sonuçlar elde etmek isteyen işletmeler bir dizi faaliyetleri önceden planlamak ve organize etmek durumundadırlar. Bunun için işin kendisinin yanı sıra işi yapana da yatırım yaparak daha verimli sonuçlar elde etmeye çalışmaktadırlar. İşlerin doğrudan denetlenmesi ile sonuç elde etmek yerine çalışanların refahına katkı sağlayarak çalışan gönüllülügüünü sağlamanın dolaylı yoldan performansı artırabileceği anlaşılmıştır (Patrick ve Paille, 2019: 2706). İşletme yönetimi, organizasyonun işlerini daha iyi yürütmek amacıyla çalışanların tutumlarını değiştirerek örgüt için faydalı davranışlar sergilemelerini amaçlamaktadır. İşletmenin çalışanlarına yönelik geliştirdiği içsel faaliyetlere olan yönetim desteği çalışanlarda örgüte güven duygusunu arttırır (Huang, 2018: 1778). Çalışan gelişimini ön planda tutarak oluşturulan örgütlenme, çalışanların tutumlarını şekillendirerek örgüte yönelik olumlu psikolojik algı beslemelerini kolaylaştıracaktır (Wei vd., 2010: 1632). Örgüte yönelik güçlü bağlllık gösteren çalışanlar ise örgütün hedeflerine 
inançlı, örgüt değerlerine bağlı ve kendini örgütün bir parçası olarak görme arzusu içinde olacaktır (Chang ve Chang, 2007: 266). Müşteri ihtiyaçlarını gözeten müşteri odaklı çalışanlar yetiştirmeyi hedefleyen örgütler çalışanların örgüt içi rollerini sahiplenmelerini ister (Fu, 2013: 50). Çalışanların, görev beklentilerinin ötesinde ekstra rol davranışları geliştirmeleriyle ortaya çıkan bu anlayış, örgüte yönelik vatandaşlık davranışına dönüşür (Ghalavi ve Nastiezaie, 2020:243). Çalışanların kuruma, işlerine ve meslektaşlarına tutumu ile ölçülen iç hizmet kalitesi çalışanların önemsenmesi, iyileştirilmesi ve kendilerine değer verildiğinin hissettirilmesi ile olabilir. Örgütlerde yürütülen içsel pazarlama faaliyetleri ile çalışanların örgüte yönelik iyi niyet duyguları geliştirmelerine yardımcı olunur. Bu sebeple örgütün içsel pazarlama uygulamalarının çalışanların ÖVD gösterme eğilimleri ile yakından ilgili olduğu öngörülmektedir (To vd., 2015: 15).

Buradan hareketle aşağıdaki hipotezlerin ortaya konması mümkün olacaktır:

$\mathrm{H}_{1}$ : İçsel pazarlama uygulamalarının (eğitim ve gelişim, ücret ve ödüllendirme, personel güçlendirme, iç iletişim) ÖVD'nın bireysel boyutu üzerinde pozitif ve anlamlı bir etkisi vardır.

$\mathrm{H}_{1 \mathrm{a}}$ : İçsel pazarlama uygulamasının eğitim ve gelişim alt boyutunun ÖVD’nın bireysel boyutu üzerinde pozitif ve anlamlı bir etkisi vardır.

$\mathrm{H}_{1 b}$ : İçsel pazarlama uygulamasının ücret ve ödüllendirme alt boyutunun ÖVD'nın bireysel boyutu üzerinde pozitif ve anlamlı bir etkisi vardır.

$\mathrm{H}_{1 c}$ : İçsel pazarlama uygulamasının personel güçlendirme alt boyutunun ÖVD'nın bireysel boyutu üzerinde pozitif ve anlamlı bir etkisi vardır.

$\mathrm{H}_{1 \mathrm{~d}}$ : İçsel pazarlama uygulamasının iç iletişim alt boyutunun ÖVD'nın bireysel boyutu üzerinde pozitif ve anlamlı bir etkisi vardır.

$\mathrm{H}_{2}$ : İçsel pazarlama uygulamalarının (eğitim ve gelişim, ücret ve ödüllendirme, personel güçlendirme, iç iletişim) ÖVD'nın örgütsel boyutu üzerinde pozitif ve anlamlı bir etkisi vardır.

$\mathrm{H}_{2 \mathrm{a}}$ : İçsel pazarlama uygulamasının eğitim ve gelişim alt boyutunun ÖVD'nın örgütsel boyutu üzerinde pozitif ve anlamlı bir etkisi vardır.

$\mathrm{H}_{2 b}$ : İçsel pazarlama uygulamasının ücret ve ödüllendirme alt boyutunun ÖVD'nın örgütsel boyutu üzerinde pozitif ve anlamlı bir etkisi vardır.

$\mathrm{H}_{2 \mathrm{c}}$ : İçsel pazarlama uygulamasının personel güçlendirme alt boyutunun ÖVD’nın örgütsel boyutu üzerinde pozitif ve anlamlı bir etkisi vardır.

$\mathrm{H}_{2 \mathrm{~d}}$ : İcsel pazarlama uygulamasının iç iletişim alt boyutunun ÖVD'nın örgütsel boyutu üzerinde pozitif ve anlamlı bir etkisi vardır.

Geliştirilen hipotezleri gösteren araştırma modeli aşağıda verilmiştir (Şekil 1).

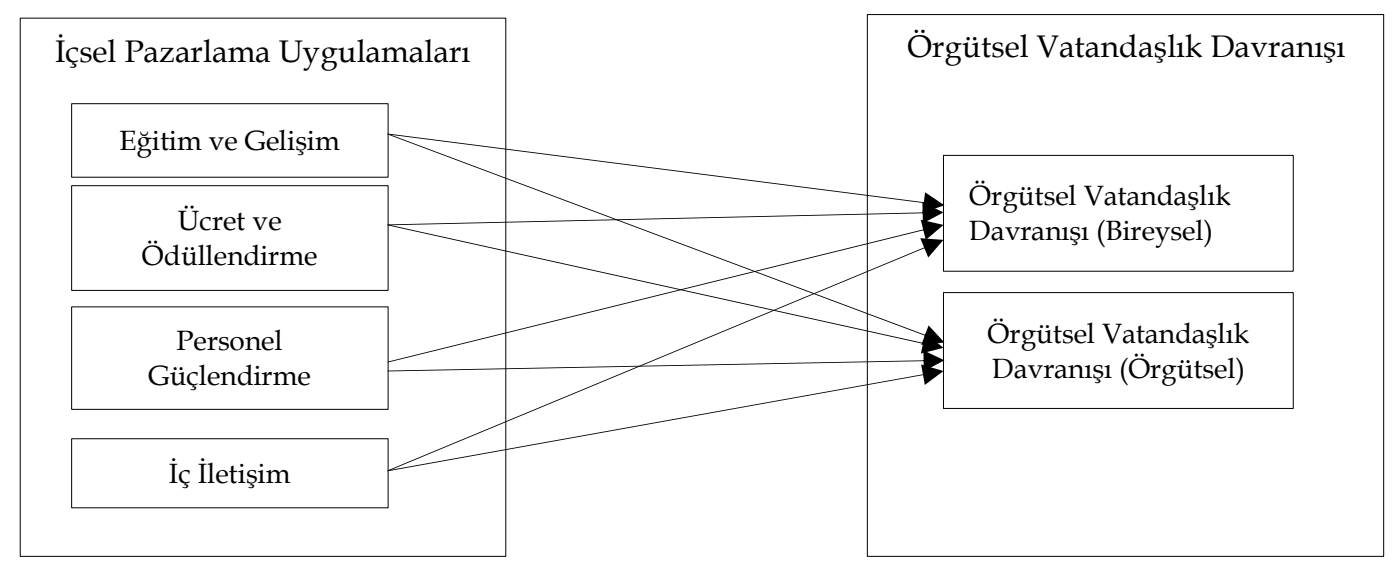

Şekil 1. Araştırma Modeli

\subsection{Araştırmanın Evreni ve Örneklemi}

Araştırmanın evrenini Trabzon'da bulunan bir kamu kurumu çalışanları oluşturmaktadır. Verilerin toplanabilmesi için anket yöntemlerinden biri olan kolayda örneklem yöntemi tercih edilmiştir. Görüşmecinin ulaşabildiği ve uygun gördüğü kişilerden anketleri doldurmasını talep 
ettiği kolayda örneklem yöntemi zaman ve maliyet açısından kısıtlı olunan durumlarda tercih edilmektedir (Nakip, 2013: 222). Bu araştırmada anketler, kurum yetkililerinden alınan izin çerçevesinde 10.05.2021-20.05.2021 tarihleri arasında 10 gün süreyle yapılabilmiştir. Bu süre zarfında çalışanlar ile yüz yüze görüşmeler yapılmış olup anketi doldurmayı kabul eden 219 çalışan ile görüşülebilmiştir. Eksik doldurulan anketler çıkarıldıktan sonra kalan 210 adet anket araştırma verisi olarak analize sokulmuştur.

\subsection{Araştırmada Kullanılan Ölçekler}

Araştırmanın anketi iki bölümden oluşmaktadır. Birinci bölümde çalışanların demografik özelliklerini (cinsiyet, yaş, öğrenim durumu, çalışma süresi, kurumdaki pozisyon) belirlemeye yönelik sorulara yer verilmiştir. İkinci bölümde ise çalışanların içsel pazarlama ve örgütsel vatandaşlık davranışlarını ölçmeye yönelik sorular yer almaktadır. Bu bölümde yer alan ölçek sorularında 5'li Likert ölçek kullanılmıştır. Ölçeklerin oluşturulmasında literatüre başvurulmuş olup, aşağıdaki referans çalışmalardan faydalanılmıştır:

\subsubsection{Araştırmada Kullanılan İçsel Pazarlama Ölçeği}

Araştırmanın bağımsız değişkeni olan içsel pazarlama değişkeni, 4 alt boyuttan oluşmakta olup, eğitim ve gelişim (6 madde), ücret ve ödüllendirme (2 madde), personel güçlendirme ( 3 madde), iç iletişim (4 madde) olarak belirlenmiştir. Eğitim ve gelişim alt boyutuna ait ölçek soru maddeleri, Ahmad ve Al-Borie (2012) ve Demo vd. (2021)'nin çalışmalarında kullanılan ölçeklerden, ücret ve ödüllendirme alt boyutuna ait soru maddeleri ise, Foreman ve Money (1995), Demir vd. (2008) ile Frye vd. (2020)'nin çalışmalarında kullanılan ölçeklerden, personel güçlendirme alt boyutuna ait soru maddeleri Narten (2012), Sahibzada vd. (2019) ile Salah vd. (2019)'nin çalışmalarında kullandıkları ölçeklerden, iç iletişim alt boyutuna ait soru maddeleri ise, Atay vd. (2017), Sahibzada vd. (2019) ile Huang ve Rundle-Thiele (2014)'nin çalışmalarında kullandıkları ölçek maddelerinden yararlanılarak yeniden geliştirilmiştir.

\subsubsection{Araştırmada Kullanılan ÖVD Ölçeği}

Araştırmanın bağımlı değişkeni olan ÖVD değişkeni ise 2 boyuttan oluşmakta olup, bireye yönelik ÖVD (7 madde), örgüte yönelik ÖVD (6 madde) olarak belirlenmiştir. ÖVD'nın bireysel ve örgütsel alt boyutlarını oluşturan ölçek maddeleri Lee ve Allen (2002)'nın çalışmasında kullanılan ölçek maddelerinden yararlanılarak geliştirilmiştir.

\section{Analiz ve Bulgular}

Tablo 1'de araştırmaya katılan çalışanların demografik özelliklerine dair bulgulara yer verilmiştir.

Tablo 1. Katılımcıların Genel Özellikleri

\begin{tabular}{|c|c|c|c|c|c|c|c|}
\hline \multicolumn{2}{|c|}{ Demografik Özellik } & \multirow{2}{*}{$\frac{\text { Frekans }}{24}$} & \multirow{2}{*}{$\begin{array}{c}\text { Yüzde } \\
11,4\end{array}$} & \multicolumn{2}{|c|}{ Demografik Özellik } & \multirow{2}{*}{$\frac{\text { Frekans }}{65}$} & \multirow{2}{*}{$\frac{\text { Yüzde }}{31}$} \\
\hline \multirow{5}{*}{ Yaş } & $19-30$ & & & \multirow{2}{*}{ Cinsiyet } & Kadın & & \\
\hline & $31-40$ & 80 & 38,1 & & Erkek & 145 & 69 \\
\hline & $41-50$ & 59 & 28,1 & \multirow{7}{*}{$\begin{array}{l}\text { Kurumdaki } \\
\text { Pozisyonu }\end{array}$} & İşçi & 89 & 42,3 \\
\hline & $51-60$ & 42 & 20 & & Memur & 25 & 11,9 \\
\hline & 60 ve üzeri & 5 & 2,4 & & Şef & 3 & 1,4 \\
\hline \multirow{8}{*}{$\begin{array}{l}\text { Çalışma } \\
\text { Süresi }\end{array}$} & 1 yıldan az & 6 & 2,9 & & Teknisyen/Tekniker & 14 & 6,7 \\
\hline & $1-5$ yil arasi & 23 & 10,9 & & Mühendis & 63 & 30 \\
\hline & 6-10 y1l aras1 & 68 & 32,4 & & Baş Mühendis/Şube Müdürü & 14 & 6,7 \\
\hline & $11-15$ yıl arası & 43 & 20,5 & & Müdür Yrd./Müdür & 2 & 1 \\
\hline & $16-20$ yıl arası & 10 & 4,8 & \multirow{4}{*}{$\begin{array}{l}\text { Öğrenim } \\
\text { Durumu }\end{array}$} & Orta Öğretim (Lise) & 54 & 25,7 \\
\hline & $21-25$ yıl arası & 18 & 8,6 & & Önlisans/Lisans & 121 & 57,7 \\
\hline & $26-30$ y1l aras1 & 11 & 5,2 & & Yüksek Lisans & 32 & 15,2 \\
\hline & 30 yıldan fazla & 31 & 14,7 & & Doktora & 3 & 1,4 \\
\hline
\end{tabular}


Araştırmaya dâhil olan katılımcıların \% 69'u erkek, \%31'i kadın katılımcılardan oluşmaktadır. Katılımcıların \%38,1'i 31-40 yaş aralığında, \%28,1'i 41-50 yaş aralığında, \%20'si 51-60 yaş aralığındadır. Katılımcıların çalışma süreleri incelendiğinde; \%33,4'ü 6-10 yıl arası, \%20,5'i 11-15 yıl arası, \%14,8'i 30 yıldan fazla çalışanlar olduğu görülmektedir. Katılımcıların öğrenim durumu incelendiğinde, \%57,6'sının önlisans/lisans, \%25,7'sinin orta öğretim (lise), \%15,2'sinin yüksek lisans, \% 1,4'ünün ise doktora mezunlarından oluştuğu anlaşılmaktadır. Katılımcıların kurumdaki pozisyonlarına bakıldığında \%42,4'ünün işçi, \%30'unun mühendis, \%11,9'unun memur pozisyonunda görev yapmakta olduğu tespit edilmiştir.

\subsection{Araştırma Ölçeklerinin Geçerlilik ve Güvenilirlik Analizleri}

Araştırma kapsamında kullanılan ölçeklerin temel bileşenlerini belirlemek amacıyla keşfedici faktör analizi uygulanmış olup, analiz sonucunda birbirinden bağımsız faktörlerin oluştuğu görülmüştür. Veri setinin faktör analizine uygun olduğunu tespit etmek amaciyla Barlett testi ve KMO testinden, araştırmanın güvenilirliğini test etmek için ise Cronbach Alfa katsayısından yararlanılmıştır.

Tablo 2. KMO ve Barlett Testi Sonuçları

\begin{tabular}{|l|l|l|}
\hline \multicolumn{2}{|c|}{ Kaiser-Meyer-Olkin } & 0,912 \\
\hline \multirow{3}{*}{ Barlett Testi } & Ki-kare & 4255,024 \\
\cline { 2 - 3 } & $\mathrm{df}$ & 378 \\
\cline { 2 - 3 } & $\mathrm{p}$ & $\mathrm{p}<0,000$ \\
\hline
\end{tabular}

Tablo 2 incelendiğinde Barlett Testi $(\mathrm{p}=0,00<0,05)$ soru değişkenleri arasında yüksek korelasyon olduğu, $\mathrm{KMO}(0,912>0,6)$ ile de faktör analizi için yeterli örneklem sayısına sahip olunduğu (Alkan ve Arıkboğa, 2017: 359) görülmektedir.

Tablo 3. Soru Değişkenlerine Ait Faktör Yükleri

\begin{tabular}{|c|c|}
\hline Faktörler & Faktör Yükü \\
\hline \multicolumn{2}{|l|}{ Ĕ̆itim ve Gelişim } \\
\hline İş yerimde, daha iyi performans elde etmem için gelişimime önem verilmektedir. & 0,633 \\
\hline İş yerimin personeline işi için verdiği eğitim, seminer, vb. yeterlidir. & 0,746 \\
\hline İş yerimde, çalışanının bilgi ve becerilerini geliştirmesi bir yatırım olarak görülmektedir. & 0,706 \\
\hline Çalışanın bilgi ve becerilerini geliştirmesi iş yerimde devam eden bir süreçtir. & 0,746 \\
\hline İş yerimde eğitim ihtiyaçları periyodik olarak belirlenmektedir. & 0,648 \\
\hline İş yerim iyi çalışanlarını gözetir. & 0,654 \\
\hline \multicolumn{2}{|l|}{ Ücret ve Ödüllendirme } \\
\hline Yaptığım işe göre aldığım maaş miktarı makuldür. & 0,841 \\
\hline Diğer iş yerlerinde benzer pozisyonlara kıyasla makul bir ücret almaktayım. & 0,828 \\
\hline \multicolumn{2}{|l|}{ Güçlendirme } \\
\hline İş yerim, çalışanların işlerini yürütürken kendi kararlarını almaları konusunda destek verir. & 0,823 \\
\hline İş yerim çalışanlarını inisiyatif alma konusunda destekler. & 0,841 \\
\hline İş yerim, çalışanların kendilerine güven duygularını güçlendirmelerini destekler. & 0,826 \\
\hline \multicolumn{2}{|l|}{ İç İletişim } \\
\hline Kurum içi iletişimde (internet, e-mail, video konferans, vb. gibi) olanaklar yeterlidir. & 0,686 \\
\hline Kurum içi iletişim iş süreçlerinin yerine getirilmesinde yeterlidir. & 0,760 \\
\hline İş yerim, personeli ile iletişiminde doğru kanalları kullanmaktadır. & 0,769 \\
\hline İş yerimde bilgi akışı hızlıdır. & 0,648 \\
\hline \multicolumn{2}{|l|}{ Örgütsel Vatandaşlık Davranışı Bireysel } \\
\hline Diğer çalışma arkadaşlarımın yokluğunda işlerine yardımcı olurum. & 0,641 \\
\hline
\end{tabular}




\begin{tabular}{|l|c|}
\hline İşi ile ilgili sorun yaşayan çalışma arkadaşlarıma yardım etmek için zaman ayırııı. & 0,745 \\
\hline İş planımı düzenlerken diğer çalış̧ma arkadaşlarımın iş planlarını dikkate alırım. & 0,630 \\
\hline İs yerimde yeni işe başlayan çalışma arkadaşlarım iş ortamına uyum sağlamalarına yardımcı olurum. & 0,731 \\
\hline İşler yoğun da olsa çalışma arkadaşlarıma ilgi ve nezaketle yaklaşırım. & 0,722 \\
\hline Problem yaşayan çalışma arkadaşlarıma yardımcı olurum. & 0,672 \\
\hline İhtiyaç duymaları halinde çalışma arkadaşlarımla kişisel eşyalarımı paylaşabilirim. & 0,533 \\
\hline Örgütsel Vatandaşlık Davranışı Örgütsel & 0,759 \\
\hline İş yerime sadık bir çalışanım. & 0,776 \\
\hline Bu iş yerinde görev yaptığım için gururluyum. & 0,595 \\
\hline İş yerimin gelişmesi için yapıcı önerilerde bulunmaktan çekinmem. & 0,795 \\
\hline İş yerimi eleştirenler olduğunda kurumumu savunurum. & 0,701 \\
\hline İş yerimi ilgilendiren gelişmeleri yakından takip ederim. & 0,771 \\
\hline İş yerimin imajı benim için önemlidir. & \\
\hline
\end{tabular}

Tablo 3'te değişkenlere ait faktör yükleri görülmektedir. Faktör analizinde faktör yükü 0,5 'in altında olan değişkenler analizden çıkartılır (Kalayc1, 329). Tablo 3'te ölçek maddelerine ait faktör yüklerinin 0,5 ve üzerinde olduğundan herhangi bir maddenin ölçekten çıkarılmasına gerek kalmadığı anlaşılmıştır.

Tablo 4. İçsel Pazarlama ve Örgütsel Vatandaşlık Davranışı Ölçeklerine ait Faktör Analizi Sonuçları

\begin{tabular}{|l|c|c|}
\hline Faktörler & Özdeğer (Eigenvalue) & Açılanan Varyans \\
\hline Eğitim ve Gelişim & 7,537 & 24,861 \\
\hline Ücret ve Ödüllendirme & 1,013 & 12,223 \\
\hline Personel Güçlendirme & 1,484 & 20,765 \\
\hline İletişim & 1,245 & 17,344 \\
\hline ÖVD Bireysel & 7,325 & 33,593 \\
\hline ÖVD Örgütsel & 1,33 & 32,987 \\
\hline
\end{tabular}

Faktör analizinde faktör sayısının belirlenmesine yönelik öz değer istatistiği (Eigenvalues) 1 ' den büyük olan faktörler anlamlı olarak belirlenebilir (Kalayc1, 2013:328). Yapılan analiz sonucunda içsel pazarlama ölçeği 4 faktörlü bir yapı oluşturmuş olup açıklanan toplam varyansı \%75,194 olarak bulunmuştur. Örgütsel vatandaşlık davranışı değişkeni ise 2 faktörlü bir yapı oluşturmuş olup açıklanan varyansı $\% 66,577$ olarak bulunmuştur.

Tablo 5. Faktörlerin Güvenilirlik Analizi Sonuçları

\begin{tabular}{|l|c|c|}
\hline \multicolumn{1}{|c|}{ Alt Boyutlar } & Güvenilirlik & Madde Sayis1 \\
\hline Eğitim ve Gelişim & 0,894 & 6 \\
\hline Ücret ve & & \\
Ödüllendirme & 0,842 & 2 \\
\hline Güçlendirme & 0,921 & 3 \\
\hline İç İletişim & 0,846 & 4 \\
\hline ÖDVB & 0,895 & 7 \\
\hline ÖDVÖ & 0,908 & 6 \\
\hline Genel & 0,940 & 28 \\
\hline
\end{tabular}

Araştırmanın güvenilirliğini ölçmek için Cronbach Alfa katsayısı kullanılmıştır. Cronbach Alfa katsayısı 0,8'in üzerindeki değerler için ölçeğin yüksek derecede güvenilir olduğu söylenebilir (Kalaycı, 2014:405). Tablo 4'te genel güvenilirlik katsayısı (Cronbach Alfa=0,940) olduğunda kullanılan ölçek yüksek derecede güvenilirdir. 


\section{2. Çoklu Regresyon ve Çoklu Doğrusallık Analizleri}

İçsel pazarlama uygulamaları olarak belirlenen eğitim ve gelişim, ücret ve ödüllendirme, personel güçlendirme, iç iletişim alt boyutlarının ÖVD'nın bireysel ve örgütsel alt boyutları üzerine etki düzeylerini belirlemeye çalıştığımız bu çalışmada ilgili hipotezlerin test edilmesi amacıyla çoklu regresyon analizi yapılmıştır. Regresyon analizi sonuçları Tablo 5 'te verilmiştir.

Tablo 6. Değişkenler Arası Çoklu Regresyon Analizi Sonuçları

\begin{tabular}{|l|c|c|c|c|c|}
\hline İlişki & $\mathrm{R}$ & $\mathrm{R}^{2}$ & Düzeltilmiş $\mathrm{R}^{2}$ & Standart Hata & Durbin Watson \\
\hline İPU=>ÖVDB & 0,458 & 0,210 & 0,194 & 0,6068 & 1,850 \\
\hline İPU=>ÖVDÖ & 0,515 & 0,265 & 0,250 & 0,6934 & 1,824 \\
\hline
\end{tabular}

Tablo 6 incelendiğinde bağımlı değişkenin yüzde kaçının bağımsız değişkenlerce açıklandı̆̆ını gösteren $\mathrm{R}^{2}$ değerleri görülmektedir. Araştırmada içsel pazarlama uygulamaları bağımsız değişkenlerinin ÖVD'nın bireysel boyutunun \%21'ini $\left(\mathrm{R}^{2}=0,210\right)$, ÖVD'nın örgütsel boyutunun ise $\% 26,5$ ' ini $\left(R^{2}=0,265\right)$ açıkladığı anlaşılmaktadır. Regresyon analizi varsayımlarına göre değişkenler arası otokorelasyonun olmaması için Durbin Watson değerinin ikinin altında kalması gerekmektedir (Akgül, 2005: 344'ten aktaran Okan vd., 2017: 252). Bu çalışmada Durbin Watson değeri (İPU=>ÖVDB $(1,85<2), \quad$ İPU=>ÖVDÖ $(1,824<2))$ olduğundan, otokorelasyon olmadı̆̆1 söylenebilir.

Tablo 7. Varyans Analizi Sonuçları

\begin{tabular}{|l|l|c|c|c|c|c|}
\hline \multirow{4}{*}{ İlişki } & \multicolumn{7}{|c|}{ Anova } & \\
\cline { 2 - 8 } & & $\begin{array}{c}\text { Kareler } \\
\text { Toplamı }\end{array}$ & $\begin{array}{c}\text { Serbestlik } \\
\text { Derecesi }\end{array}$ & $\begin{array}{c}\text { Ortalamanın } \\
\text { Karesi }\end{array}$ & F & $\mathrm{p}$ \\
\hline \multirow{4}{*}{ İPU=>ÖVDB } & Regresyon & 20,029 & 4 & 5,007 & 13,596 & 0,000 \\
\cline { 2 - 8 } & Kalınt1 & 75,498 & 205 & 0,368 & & \\
\cline { 2 - 8 } & Total & 95,527 & 209 & & & \\
\hline \multirow{3}{*}{ IPU=>ÖVDÖ } & Regresyon & 35,494 & 4 & 8,874 & 18,455 & 0,000 \\
\cline { 2 - 8 } & Kalınt1 & 98,57 & 205 & 0,481 & & \\
\cline { 2 - 8 } & Total & 134,064 & 209 & & & \\
\hline
\end{tabular}

Tablo 7'de varyans analizi sonuçlarını gösteren Anova tablosunda içsel pazarlama uygulamalarının ÖVD'nın bireysel boyutu üzerine etkisini test eden analizde F=13,596 ve anlamlılık düzeyi p<0,000, içsel pazarlama uygulamalarının ÖVD'nın örgütsel boyutu üzerine etkisini test eden analizde ise $F=18,455$ ve anlamlılık düzeyi $p<0,000$ olarak bulunmuştur. Bu sonuçlardan hareketle modelin bir bütün olarak anlamlı olduğu söylenebilir.

Tablo 8. Çoklu Doğrusallık Analizi Sonuçları

\begin{tabular}{|c|c|c|c|c|c|c|c|c|}
\hline & \multirow[t]{2}{*}{ Model } & \multicolumn{2}{|c|}{$\begin{array}{l}\text { Standardize Edilmemiş } \\
\text { Katsayılar }\end{array}$} & \multirow{2}{*}{$\begin{array}{c}\text { Standardize } \\
\text { Edilmiş } \\
\text { Katsayilar } \\
\text { BETA }\end{array}$} & \multirow[t]{2}{*}{$\mathrm{t}$} & \multirow[t]{2}{*}{$\mathrm{p}$} & \multicolumn{2}{|c|}{$\begin{array}{c}\text { Doğrusallık } \\
\text { (Collinearity) } \\
\text { İstatistikleri }\end{array}$} \\
\hline & & $\mathrm{B}$ & Standart Hata & & & & Tolerans & VIF \\
\hline \multirow{5}{*}{ ÖVDB } & (Sabit) & 3,003 & 0,181 & & 16,627 & 0,000 & & \\
\hline & Eğitim ve Gelişim & 0,155 & 0,048 & 0,28 & 3,21 & 0,002 & 0,505 & 1,98 \\
\hline & Ücret ve Ödüllendirme & 0,047 & 0,04 & 0,085 & 1,192 & 0,235 & 0,75 & 1,333 \\
\hline & Personel Güçlendirme & $-0,129$ & 0,075 & $-0,16$ & $-1,713$ & 0,088 & 0,442 & 2,262 \\
\hline & İç İletişim & 0,225 & 0,063 & 0,305 & 3,589 & 0,000 & 0,534 & 1,874 \\
\hline ÖVDÖ & (Sabit) & 2,647 & 0,206 & & 12,825 & 0,000 & & \\
\hline
\end{tabular}




\begin{tabular}{|l|l|c|c|c|c|c|c|c|c|}
\hline & Eğitim ve Gelişim & 0,229 & 0,055 & 0,35 & 4,158 & 0,000 & 0,505 & 1,98 \\
\cline { 2 - 8 } & Ücret ve Ödüllendirme & 0,042 & 0,045 & 0,065 & 0,936 & 0,350 & 0,75 & 1,333 \\
\cline { 2 - 8 } & Personel Güçlendirme & $-0,034$ & 0,086 & $-0,036$ & $-0,4$ & 0,690 & 0,442 & 2,262 \\
\cline { 2 - 8 } & İç İletişim & 0,191 & 0,072 & 0,218 & 2,659 & 0,008 & 0,534 & 1,874 \\
\hline
\end{tabular}

Tablo 8 incelendiğinde değişkenlere ait hesaplanan VIF değerlerinin VIF $<10$ olması sebebiyle modelde çoklu doğrusal bağlantı probleminin (multicollinearity) olmadığı söylenebilir (Kalaycı, 2014: 268).

\subsection{Hipotezlerin Test Edilmesi}

" $\mathrm{H}_{1}$ : İçsel pazarlama uygulamalarının (eğitim ve gelişim, ücret ve ödüllendirme, personel güçlendirme, iç iletişim) ÖVD'nın bireysel boyutu üzerinde pozitif ve anlamlı bir etkisi vardır" şeklinde oluşturulan hipotezle ilgili olarak Tablo 7 incelendiğinde, ÖVD'nın bireysel boyutu üzerindeki etkileri açısından gerek eğitim ve gelişim alt değişkeninin etkisinin $(p<0,002)$ gerekse de iç iletişim alt değişkeninin etkisinin pozitif ve anlamlı $(\mathrm{p}<0,000)$ çıktığı anlaşılmaktadır. Buradan hareketle $\mathrm{H}_{1 a}$ ve $\mathrm{H}_{1 \mathrm{~d}}$ alt hipotezleri kabul edilmiştir. Öte yandan ücret ve ödüllendirme alt değişkeninin etkisi $(p<0,235)$ ile personel güçlendirme alt değişkeninin etkisi $(p<0,088)$ anlamsız çıktığından $\mathrm{H}_{1 \mathrm{~b}}$ ve $\mathrm{H}_{1 \mathrm{c}}$ alt hipotezleri reddedilmiştir.

" $\mathrm{H}_{2}$ : İçsel pazarlama uygulamalarının (eğitim ve gelişim, ücret ve ödüllendirme, personel güçlendirme, iç iletişim) ÖVD'nın örgütsel boyutu üzerinde pozitif ve anlamlı bir etkisi vardır" şeklinde oluşturulan hipotezle ilgili olarak Tablo 7 incelendiğinde ise, ÖVD'nın örgütsel boyutu üzerindeki etkileri açısından gerek eğitim ve gelişim alt değişkeninin etkisinin $(p<0,000)$ gerekse de iç iletişim alt değişkeninin etkisinin $(p<0,008)$ pozitif ve anlamlı çıktığ $\breve{l}_{1}$ anlaşılmaktadır. Buradan hareketle $\mathrm{H}_{2 \mathrm{a}}$ ve $\mathrm{H}_{2 \mathrm{~d}}$ alt hipotezleri kabul edilmiştir. Öte yandan ücret ve ödüllendirme alt değişkeninin etkisi $(p<0,350)$ ile personel güçlendirme alt değişkeninin etkisi $(p<0,690)$ anlamsız çıtı ğından $\mathrm{H}_{2 b}$ ve $\mathrm{H}_{2 \mathrm{c}}$ alt hipotezleri reddedilmiştir.

$\mathrm{Bu}$ bulgular çerçevesinde bağımsız değişkenlerin bağımlı değişkenler üzerindeki etkisini gösteren regresyon denklemleri aşağıda verilmiştir:

ÖVDB $=3,003+($ Eğitim ve Gelişim $) \times 0,155+($ İç İletişim $) \times 0,225$

ÖVDÖ $=2,647+($ Eğitim ve Gelişim $) \times 0,229+($ İç İletişim $) \times 0,191$

Bu modelde ÖVD'nın bireysel boyutuna eğitim ve gelişim alt faktörünün 0,155 katsayılık bir etkisi olduğu, iç iletişim faktörünün ise 0,225 katsayılık bir etkisi olduğu anlaşılmıştır. ÖVD'nın örgütsel boyutuna eğitim ve gelişim alt faktörünün 0,229 katsayılık bir etkisi olduğu, iç iletişim alt faktörünün ise 0,191 katsayılık bir etkisi olduğu anlaşılmıştır.

\section{Sonuç ve Değerlendirme}

İşletmelerin paydaşlarına sundukları hizmet kalitesini artırmanın önemli bir yolu da hizmeti sağlayan çalışanların başarısından geçmektedir. Çalışan başarısını artırmak ancak onları motive edecek, kişisel gelişimine katkı sağlayacak, işlerini yürütmede kolaylık sağlayacak bir dizi uygulamanın faaliyete geçirilmesi ile mümkündür. İşin doğası gereği işinde tatmin olan çalışanın örgüte yönelik daha olumlu duygular içerisinde olabileceği varsayılmaktadır.

Literatürde içsel pazarlama uygulamaları olarak yer alan bu faaliyetlerin örgütsel vatandaşlık davranışına etki düzeyini araştırdığımız bu çalışmanın bulguları çerçevesinde içsel pazarlama uygulamalarının alt faktörleri olan eğitim ve gelişim, iç iletişim boyutlarının ÖVD'nin bireysel boyutu üzerinde anlamlı etkilerinin olduğu tespit edilmiştir. Bu sonuçlar benzer değişkenlerle araştırma yapan Patrick ve Paille (2019), Pham vd. (2019), Akın (2019), Demirel ve Güner (2015), Akgemci ve Koçyiğit (2013), çalışmalarının sonuçları ile örtüşmektedir. Teknolojinin gelişmesi ile birlikte birçok sektörde işlerin yapılış şekilleri de değişmektedir. Bu değişime çalışanların uyum sağlamaları ancak alınacak eğitim ve sektöre yönelik gelişim faaliyetleri ile olabilmektedir. Ayrıca birimler ve çalışanlar arası koordinasyonun sağlanması amacıyla uygulanan iletişim yöntemleri çalışanların birbiri ile olan irtibatını artırarak kuruma olan aidiyeti geliştirecektir. Çalışma kapsamında belirlenen diğer içsel pazarlama uygulamaları olan ücret ve ödüllendirme ile personel güçlendirme boyutlarının ÖVD'nın bireysel ve örgütsel boyutları üzerinde anlamlı bir etkisinin olmadığ1 bulunmuştur. İlgili literatürde Wei vd. (2010)'nin de benzer sonuçlar elde ettiği 
görülmektedir. Bu durum örgütün çalışanlara yönelik uyguladığı ücret, ödüllendirme ve personel güçlendirme politikalarının çalışanlarda fark edilir düzeyde bir etki oluşturmadığını göstermektedir. Bu anlamda kurumun geliştireceği daha farklı yeni politikalar ile çalışanların örgüte yönelik bağlılığı artırılabilir.

Çalışana yatırım yapmak dolaylı da olsa aslında işletmeye yatırım yapmak demektir. Bilgi ve becerisi artmış, öz güveni yüksek, gelecek için fikir üretebilen çalışanlar işletmenin geleceğini daha iyi bir noktaya taşımada en önemli unsur kabul edilmelidir. Bu sebeple bu araştırmanın sonuçlarından da hareketle işletmelerin çalışanlarına yapacakları gerekli eğitim ve yatırımları önemsemeleri ve bunu sürekli ve sürdürülebilir kılmaları büyük önem arz etmektedir.

$\mathrm{Bu}$ çalışmanın kısıtlarından birini sadece bir kamu kurumu çalışanları üzerinde uygulanmış olması oluşturmaktadır. Bu çerçevede gelecekteki araştırmalar için daha geniş bir örneklemin kullanıldığı ve farklı değişkenlerin de dâhil edildiği farklı modellerin test edilmesi ilgili alana katkı sağlayacaktır.

\section{Kaynakça}

Ahmad, Alaeddin Mohammad Khalaf ve Hussein Mohammad Al-Borie (2012). "Impact of internal marketing on job satisfaction and organizational commitment: A study of teaching hospitals in Saudi Arabia", Business and Management Research, 1, 3, 82-94.

Ahmed, Pervaiz K. ve Mohammed Rafiq (1995). "The role of internal marketing in the implementation of marketing strategies". Journal of Marketing Practice: Applied Marketing Science, $1,4,32-51$

Akgemci, Tahir ve Nezahat Koçyiğit (2013). “İnsan kaynaklarında eğitim ve geliştirme faaliyetlerinin örgütsel vatandaşlık davranışı üzerindeki etkilerinin incelenmesi". Humanitas, 1 , 17-31.

Akın, Mahmut (2019). "İnsan kaynakları uygulamalarının iş tatmini ve örgütsel vatandaşlık davranışlarına etkisi". Anadolu Akademi Sosyal Bilimler Dergisi, 1, 111-131.

Alkan, Deniz Palalar ve F. Şebnem Arıkboğa (2017). “Etik liderlik ve örgütsel vatandaşlık davranışı ilişkisinde örgütsel özdeşleşmenin aracilık etkisi ve bir uygulama". Yönetim ve Ekonomi, 24, 2, 349-369.

Amah, Okechukwu Ethelbert (2020), "Innovative work behaviors: role of employee engagement \& organizational citizenship behaviors". The Indian Journal of Industrial Relations, 56, 2, 356-373.

Amin, Ruhul; Alamgir Hossain ve Abdullah Al Masud (2020), “Job stress and organizational citizenship behavior among university teachers within Bangladesh: mediating influence of occupational commitment". Management, 24, 2, 107-131.

Arnett, Dennis B.; Debra A. Laverie ve Charlie McLane (2002), “Using job satisfaction and pride as internal marketing tools". Cornell Hotel \& Restaurant Administration Quarterly, 43, 2, 87-96.

Atay, Lütfi; Yasin Soylu ve H. Mehmet Yıldırım (2017). "Otel işletmelerinde uygulanan içsel pazarlama faaliyetlerinin çalışanların duygusal bağlllık tutumlarına etkisi: Çanakkale örneği". Uluslararası Sosyal Araştırmalar Dergisi, 10, 49, 532-541.

Ay, Canan ve Burak Kartal (2003). "İçsel pazarlama: Literatür incelemesi". Öneri, 5, 20, 15-25.

Basım, H. Nejat ve Harun Şeşen (2006). “Örgütsel vatandaşlık ölçeği uyarlama ve karşılaştırma çalışması”. Ankara Üniversitesi SBF Dergisi, 61, 4, 83-101.

Caruana, Albert ve Peter Calleya (1998). "The effect of internal marketing on organizational commitment among retail bank managers". International Journal of Bank Marketing, 16, 3, 108-116.

Chan, Sow Hup Joanne ve Oi Mei Kim Kuok (2021). "Antecedents of civic virtue and altruistic organizational citizenship behavior in Macau". Society and Business Review, 16, 1, 113-133.

Chang, Ching-Sheng ve Hsin-Hsin Chang (2007), "Effects of internal marketing on nurse job satisfaction and organizational commitment: Example of medical centers in Southern Taiwan". Journal of Nursing Research, 15, 4, 265-274.

Cioclov, Roxana; Remus Ionu Naghi ve Monica Boldea (2016). "Complementarity between the functions and instruments of internal marketing and human resource management". Management \& Marketing, 14, 1, 57-78. 
Çavuş, Mustafa Fadai ve Mehmet Biçer (2021). "The effects of organizational democracy on organizational citizenship behaviours". Manas Sosyal Araştırmalar Dergisi, 10, 1, 387-396.

Demir, Halis; Resul Usta ve Tarhan Okan (2008). "İçsel pazarlamanın örgütsel bağlılık ve iş tatminine etkisi". H.Ü. İktisadi ve İdari Bilimler Fakültesi Dergisi, 26, 2, 135-161.

Demirel, Yavuz ve Ebru Güner (2015). "İç müşteri ilişkileri yönetiminin örgütsel vatandaşlık davranışı üzerine etkisi". Uluslararası Alanya İşletme Fakültesi Dergisi, 7, 2, 1-14.

Demo, Gisela; Elaine Rabelo Neiva; Iara Nunes ve Kesia Rozzett (2021). "Human resources management policies and practices scale (HRMPPS): Exploratory and confirmatory factor analysis". Human Resources Management Policies and Practices Scale, 4, 2, 395-420.

Foreman, Susan K. ve Arthur H. Money (1995). "Internal marketing: Concepts, measurement and Application". Journal of Marketing Management, 11, 8, 755-768.

Frye, William D.; Soonhwa Kang; Chang Huh ve Myong Jae Lee (2020). "What factors influence generation $\mathrm{Y}^{\prime}$ 's employee retention in the hospitality industry? An internal marketing approach". International Journal of Hospitality Management, 85, 1-9.

$\mathrm{Fu}$, Yan-Kai (2013). "The influence of internal marketing by airlines on customer-oriented behavior: A test of the mediating effect of emotional labor". Journal of Air Management, 32, 49-57.

George, William R. (1990). "Internal marketing and organizational behavior: A partnership in developing customer-conscious employees at every level". Journal of Business Research, 20, 63-70.

Ghalavi, Zahra ve Naser Nastiezaie (2020). "Relationship of servant leadership and organizational citizenship behavior with mediation of psychological empowerment", Eurasian Journal of Educational Research, 89, 241-264.

Gounaris, Spiros P. (2006). "Internal-market orientation and its measurement", Journal of Business Research, 59, 432-448.

Huang, Shien-Ping (2018). “Impact of internal marketing management on organizational citizenship behavior based on organizational commitment in ecological industry". Ekoloji, 27, 106, 17751783.

Huang, Yu-Ting ve Sharyn Rundle-Thiele (2014). “The moderating effect of cultural congruence on the internal marketing practice and employee satisfaction relationship: An empirical examination of Australian and Taiwanese born tourism employees". Tourism Management, 42, 196-206.

İplik, Esengül; Fatma Nur İplik ve İ. Efe Efeoğlu (2014). “Çalışanların örgütsel destek algılarının örgütsel vatandaşlık davranışı üzerindeki etkisinde örgütsel özdeşleşmenin rolü". International of Economic and Administrative Studies, 6, 12, 109-122.

Kalaycı, Ş. (2014). SPSS uygulamalı çok değişkenli istatistik teknikleri. 6. Baskı, Ankara: Asil Yayın Dağıtım.

Lee, Kibeom ve Natalie J. Allen (2002). “Organizational citizenship behavior and workplace deviance: the role of affect and cognitions". The Journal of Applied Psychology, 87, 1, 131-142.

Liu, Zonghua; Shiye Mei ve Yulang Guo (2020). “Green human resource management, green organization identity and organizational citizenship behavior for the environment: the moderating effect of environmental values", Chinese Management Studies, 15, 2, 290-304.

Mac, Lancy ve Ho Kit Ieng Shirley (2015). “The Impact of internal marketing on organizational commitment: The mediating roles of customer orientation and internal communication". Euro Asia Journal of Management, 25, 1, 3-13.

Moorman, Robert H. ve Gerald L. Blakely (1995). “Individualism-collectivism as an individual difference predictor of organizational citizenship behaviour", Journal of Organizational Behavior, $16,2,127-142$.

Nakip, Mahir (2013), Pazarlama Araştırmalarına Giriş, 4. Baskı, Seçkin Yayıncılık

Narten, Bedman (2012). "Internal marketing and employee commitment: Evidence from the Ghanaian banking industry". Journal of Financial Services Marketing, 17, 4, 284-300.

Newman, Alexander; Qing Miao; Peter S. Hofman ve Cherrie Jiuhua Zhu (2016). "The impact of socially responsible human resource management on employees' organizational citizenship 
behaviour: the mediating role of organizational identification". The International Journal of Human Resource Management, 27, 4, 440-455.

Okan, Tarhan; Halis Demir ve Sedat Bostan (2017). "Prosedür adaleti algısı ve örgütsel vatandaşlık davranışı-birey ilişkisine durumsal bir bakış: yüksek ve düşük psikolojik sermaye etkisi". International Journal of Economic and Administrative Studies, 18, 237-262.

Organ, Dennis W. ve Katherine Ryan (1995). "A meta-analytic review of attitudinal and dispositional predictors of organizational citizenship behaviour", Personal Psychology, 48, 775-801.

Pham, Nhat Tan; Zuzana Tucková ve Charbel José Chiappetta Jabbour (2019). "Greening the hospitality industry: How do green human resource management practices influence organizational citizenship behavior in hotels? A mixed-methods study", Tourism Management, 72, 386-399.

Podsakoff, Philip M.; Scott B. MacKenzie; Julie Beth Paine ve Daniel G. Bachrach, (2000). "Organizational citizenship behaviors: A critical review of the theoretical and empirical literature and suggestions for future research", Journal of Management, 26, 3, 513-563.

Pratiwi, Pratiwi ve Aini Zahra Salsabiela (2015). “The Impact of Strategic Human Resources Management to Organizational Citizenship Behavior for the Environment in Manufacturing Company". Asia-Pacific Management and Business Application, 4, 2, 32-47.

Sahibzada, Umar Farooq; Cai Jianfeng, Fawad Latif ve Zahid Shafait (2019). “Development and validation of a multidimensional instrument for measuring internal marketing in Chinese higher education". Journal of Enterprise Information Management, 32, 3, 413-435.

Salah, Marwa; Mohamed Abou-Shouk ve Nancy M. Fawzy (2019). "Exploring the impact of internal marketing on organizational commitment of travel agents' employees". International Journal of Hospitality $\mathcal{E}$ Tourism Systems, 12, 1, 1-12.

To, W.M.; E. F. Martin ve Billy T.W. Yu (2015). "Effect of management commitment to internal marketing on employee work attitude". International Journal of Hospitality Management, 45, 14-21.

Patrick, J. Valeau ve Pascal Paille (2019). “The management of professional employees: linking progressive HRM practices, cognitive orientations and organizational citizenship behavior". The International Journal of Human Resource Management, 30, 19, 2705-2731.

Van Dyne, Linn; Jill W. Graham ve Richard M. Dienesch (1994). “Organizational citizenship behavior: construct redefinition, measurement, and validation". Academy of Management, 37, 4, 765-802.

Wei, Yu-Chen; Tzu-Shian Han ve I-Chieh Hsu (2010). “High-performance HR practices and OCB: A cross level investigation of a causal path". The International Journal of Human Resource Management, 21, 10, 1631-1648.

Williams, Larry J. ve Stella E. Anderson (1991). “Job satisfaction and organizational commitment as predictors of organizational citizenship and in-role behaviors". Journal of Management, 17, 3, 601617.

Zhao, Hongdan; Qiongyao Zhou; Peixu He ve Cuiling Jiang (2019). “How and when does socially responsible HRM affect employees' organizational citizenship behaviors toward the environment?", Journal of Business Ethics, 169, 371-385.

\section{Extended Abstract}

\section{Aim and Scope}

Businesses that want to achieve more efficient results in their business have to plan and organize a series of activities in advance. For this, they try to achieve more efficient results by investing in the person doing the work as well as the work itself. It has been understood that instead of obtaining results by direct supervision of the works, providing employee volunteering by contributing to the welfare of the employees can indirectly increase performance (Patrick and Paille, 2019: 2706). Business management aims to show beneficial behaviours for the organization by changing the attitudes of the employees in order to carry out the business of the organization better. Management support for internal activities developed by the enterprise for its employees increases the sense of trust in the organization in employees (Huang, 2018: 1778). The organization created by prioritizing 
employee development will shape the attitudes of employees and facilitate their positive psychological perception towards the organization (Wei et al., 2010: 1632). Employees who show a strong commitment to the organization will be faithful to the goals of the organization, committed to the values of the organization and will have the desire to see themselves as a part of the organization (Chang and Chang, 2007: 266). Organizations that aim to raise customer-oriented employees who take care of customer needs want employees to own their roles within the organization (Fu, 2013: 50). This understanding, which emerges when employees develop extra role behaviours beyond their job expectations, turns into citizenship behaviour towards the organization (Ghalavi and Nastiezaie, 2020:243). Internal service quality, which is measured by the attitude of the employees to the institution, their jobs and their colleagues, can be achieved by caring, improving and making them feel valued. With internal marketing activities carried out in organizations, employees are helped to develop goodwill towards the organization. For this reason, it is predicted that the internal marketing practices of the organization are closely related to the tendency of employees to Show Organizational Citizenship Behaviour (OCB) (To et al., 2015: 15).

When the literature on the subject is examined, Zhao et al. (2019) investigated the effect of socially responsible human resources practices on employees' OCB towards the environment within the framework of person-organization fit, and found that human resources practices had a positive and significant effect on employees' OCB.

Liu et al. (2020) investigated the relationship between green organizational identity and environmental OCB variables of human resources management implemented within the framework of the green concept, and found that green human resources management had a significant and positive effect on organizational citizenship behaviour towards the environment, and that green organizational identity also played a mediating role here.

Patrick and Paille (2019), in their research examining the mediating role of perceived organizational support, job satisfaction and organizational commitment in the effect of human resources practices on OSB, determined that human resources practices in the form of justice and reward, talent development and promotion have a significant effect on OCB.

Akın (2019), in his study examining the effects of human resources practices on job satisfaction and organizational citizenship behaviours, revealed that selection, incentive, training and development practices, which are determined as human resources practices, have a positive and significant effect on employees' OCB.

Pham et al. (2019) investigated the effects of green human resources practices on employees' OCB towards the environment. They revealed that the sub-dimensions of education, performance management, and employee participation had positive and significant effects on environmental OCB.

Huang (2018) examined the possible relationships between internal marketing management, organizational commitment and OCB variables in his study and found that internal marketing management and organizational commitment had a positive and significant effect on OCB.

Newman et al. (2016) examined the effect of socially responsible human resources practices on employees' OCB and the possible mediating role of organizational identity in this relationship. As a result of their study, it has been determined that employee-oriented HR and corporate social responsibility practices in general have positive and significant effects on OCB of employees.

On the other hand, Pratiwi and Salsabiela (2015) determined that strategic human resource management practices have significant contributions to OCB towards the environment.

In their research, Demirel and Güner (2015) revealed that the dimensions of leadership, cooperation and communication, technological competence, internal customer orientation and employee satisfaction, which are determined as the sub-dimensions of internal customer relations in enterprises, have significant effects on employees' OCB.

Wei et al. (2010) found that the sub-dimensions of internal career opportunities, training, employee safety, participation and communication, sensitive selection, incentive cost, which were determined as high-performance human resources practices, did not have a significant effect on the organizational citizenship behaviours of the employees. 
Akgemci and Koçyiğit (2013) investigated the effects of training and development activities in human resources on OCB. It has been determined that the dimensions of perceived educational opportunities, learning motivation in education programs and expected individual gains from education, which are sub-dimensions of training and development activities, positively affect OCB. On the other hand, it has been determined that the dimensions of perceived supervisor support for education, support of colleagues and career expectations related to education do not have a significant effect on OCB.

\section{Methodology}

The population of the research consists of employees of a public institution in Trabzon. Convenience sampling method was used in the sample selection of the study. A survey was conducted with the employees for 10 days at the beginning of 2020, by obtaining the necessary permissions from the relevant institution officials. A total of 219 employees were reached, and after the incomplete questionnaires were removed, the remaining 210 questionnaires were analysed as research data.

\section{Scales Used in the Research}

The questionnaire of the research consists of two parts. In the first part, questions to determine the demographic characteristics of the employees (gender, age, education level, working time, position in the institution) were included. In the second part, there are questions to measure the internal marketing and organizational citizenship behaviours of the employees. A 5-point Likert scale was used in the scale questions in this section.

The internal marketing variable, which is the independent variable of the research, consists of 4 sub-dimensions and was determined as training and development ( 5 items), wages and rewards (3 items), personnel empowerment (3 items), and internal communication (4 items). The OCB variable, which is the dependent variable of the research, consists of 2 dimensions, and it was determined as OCB for the individual (7 items) and OCB for the organization (6 items).

\section{Analysis and Findings}

In order to determine the basic components of the scales used within the scope of the research, exploratory factor analysis was applied and it was observed that independent factors were formed as a result of the analysis. Barlett test and KMO test were used to determine that the data set was suitable for factor analysis, and the Cronbach Alpha coefficient was used to test the reliability of the study. As a result of the Barlett Test $(p=0.00<0.05)$, it was seen that there was a high correlation between the question variables, and that the KMO $(0.912>0.6)$ test had sufficient sample size for factor analysis (Alkan \& Arikboğa, 2017: 359).

When the scale items were examined, it was understood that there was no need to remove any item from the scale since the factor loads of the items were 0.5 and above. The total explained variance of the variables was found to be $72.44 \%$, and it was observed that a structure with 6 factors was formed in total. The internal marketing scale is grouped under 4 factors as training and development, compensation and rewarding, empowerment and internal communication, and the OCB scale is grouped under 2 factors as individual and organizational. Cronbach Alpha was used to measure the reliability of the study, and the reliability value found (Cronbach Alpha $=0.940$ ) was high.

In this study, multiple regression analysis was performed to test the related hypotheses. When the results of the regression analysis are examined; it is understood that the independent variables of internal marketing practices explain $21 \%$ of the individual dimension of OCB $\left(\mathrm{R}^{2}=0.210\right)$, while it explains $26.5 \%$ of the organizational dimension of OCB $\left(\mathrm{R}^{2}=0.265\right)$. In this study, it can be said that there is no autocorrelation since the Durbin Watson value [IPU=>OVWP $(1.85<2)$, IPU $=>$ OCBQ $(1.824<2)]$. Since the calculated VIF values of the variables are VIF $<10$, it can be said that there is no multicollinearity problem in the model.

\section{Conclusion and Evaluation}

As a result of the findings obtained by the analysis of the data; it has been observed that the subdimensions of internal marketing activities: training and development and internal communication sub-dimensions have positive and significant effects on both the individual citizenship behaviour 
and organizational citizenship behaviour sub-dimensions, which constitute the organizational citizenship behaviour variable. It has been determined that the wage and reward dimension and the personnel empowerment dimension, which are among the other sub-dimensions, do not have a significant effect.

One of the limitations of this study is that it was applied only to the employees of a public institution. In this context, testing different models in which a larger sample is used and different variables are included for future research will contribute to the relevant field. 